\title{
Ordenación territorial y acceso a la tierra en la Amazonia brasileña: los asentamientos rurales de reforma agraria y las reservas extractivistas
}

\author{
Territorial planning and access to the land in the Brazilian amazon: the Rural settlements of \\ agrarian reform and extractive reserves
}

Ordenamento territorial e acesso à terra na Amazônia brasileira: os assentamentos rurais de reforma agrárias e as reservas extrativistas

Fernanda Machado Ferreira

ORCID: https://orcid.org/0000-0001-9452-4267 Universidade Federal de Viçosa, Brasil

E-mail: fernanda.machado@ufv.br José Ambrósio Ferreira Neto

ORCID: https://orcid.org/0000-0002-1173-4582 Universidade Federal de Viçosa, Brasil E-mail: ambrosio@ufv.br

Flora Magdaline Benitez Romero ORCID: https://orcid org/0000-0001-9417-1780 Instituto Nacional de Pesquisas da Amazônia, Brasil E-mail: benitezmagdaline@gmail.com

Mariane Paulina Batalha Roque

ORCID: https://orcid.org/0000-0001-5267-1007 Universidade Federal de Viçosa, Brasil E-mail: marianepr.batalha@gmail.com

\begin{abstract}
Resumen
La implementación del proyecto de modernización capitalista en la Amazonia brasileña, a partir de 1964, intensificó el proceso de ocupación de este territorio, resultando en su reconfiguración y en la emergencia de conflictos asociados a la lucha por la tierra. El presente artículo tiene como objetivo analizar, comparativamente, las diferentes formas de uso y ocupación del territorio en los Asentamientos Rurales de Reforma Agraria y en las Reservas Extractivistas y cómo interfieren en la dinámica ambiental en la Amazonia brasileña. Como metodología se buscó articular conceptualmente elementos asociados a la Ordenación Territorial con la dimensión empírica derivada de los modelos y formas de apropiación del territorio conducidos por el Estado. Se verificó que los patrones de uso y ocupación en esos territorios impactan de formas diferentes al bioma amazónico. El estudio permitió concluir que las Reservas Extractivistas se presentan como un modelo de organización del territorio que está en sintonía con las singularidades ambientales y socioculturales de la Amazonia, mientras que los Asentamientos Rurales, por su propia naturaleza, contribuyen para la conversión del bosque en otros usos, como la agricultura y la ganadería.
\end{abstract}

Palabras clave: Amazonia; Ordenación territorial; Asentamientos rurales de reforma agraria; Reservas extractivistas.

\begin{abstract}
The implementation of the capitalist modernization project in the Brazilian Amazon from 1964 intensified the process of occupation of this territory, resulting in its reconfiguration and emergence of conflicts associated with the struggle for land. This article aims to analyse how the different forms of use and occupation of the territory in Rural Settlements and the Extractive Reserves affect the environmental dynamics in the Brazilian Amazon. It attempted to articulate conceptual elements associated with the Territorial Planning with the empirical dimension originated from models and forms of appropriation of the territory conducted by the state. It was found that the patterns of use and occupation of these territories impact in different ways the Amazon Biome, and the Extractive reserves are presented as a model of territorial organization that is in tune with the environmental and socio-cultural singularities of the Amazon, by their nature, contribute to forest conversion in other uses, such as agriculture and livestock.
\end{abstract}

Keywords: Amazon; Territorial planning; Extrativist reserves; Rural settlements agrarian reform.

\section{Resumo}

A implantação do projeto de modernização capitalista na Amazônia brasileira, a partir de 1964, intensificou o processo de ocupação desse território, resultando em sua reconfiguração e no surgimento de conflitos associados à luta pela terra. O presente artigo tem como objetivo analisar, comparativamente, as diferentes formas de uso e 
ocupação do território nos Assentamentos Rurais da Reforma Agrária e nas Reservas Extrativistas e como elas interferem na dinâmica ambiental na Amazônia Legal. Como metodologia, buscou-se articular conceitualmente os elementos associados ao Ordenamento do Território com a dimensão empírica derivada dos modelos e formas de apropriação do território liderados pelo Estado. Verificou-se que os padrões de uso e ocupação desses territórios impactam o bioma Amazônia de diferentes formas. O estudo permitiu concluir que as Reservas Extrativistas se apresentam como um modelo de organização do território que está em sintonia com as singularidades ambientais e socioculturais da Amazônia, enquanto os Assentamentos Rurais, por sua própria natureza, contribuem para a conversão da floresta. em outros usos, como agricultura e pecuária.

Palavras-chave: Amazônia; Ordenamento territorial; Assentamentos rurais de reforma agrária; Reservas extrativistas.

\section{Introducción}

El proyecto de modernización capitalista de la Amazonia brasileña, a partir de 1964, resultó una intensificación del proceso de su ocupación y de un conjunto de transformaciones políticas, sociales, económicas y ambientales que impactaron directamente ese territorio y sus formas tradicionales de uso y apropiación (Becker, 2001; Becker, 2005. Este proyecto se basó en la implementación de grandes emprendimientos, especializados en diferentes actividades económicas, sobre todo las dirigidas a la agricultura, ganadería y minería, apoyándose en estrategias territoriales de ampliación de las redes de integración nacional, como la apertura de carreteras y la ampliación de las redes de telecomunicaciones, así como el incentivo a la ocupación del territorio, por medio de la creación de proyectos de colonización (Silva et al, 2020; Rosário et al, 2021). Como resultado, se verificó una rápida y expresiva ampliación del contingente poblacional en la región y una considerable intensificación de los procesos de deforestación (Ferrante et al, 2021; Carrero et al, 2020). Además, se intensificaron los conflictos agrarios derivados de la expulsión de las poblaciones locales de sus territorios para la implantación de los proyectos agropecuarios, lo que posteriormente implicó en la creación de políticas e instrumentos de organización del territorio amazónico relacionados a la garantía del acceso a la tierra (Becker, 2001; Becker, 2005; Angelo \& Sá, 2007; Souza, 2010; Rabello, 2015). Este trabajo tiene como foco dos de esos instrumentos de organización territorial: los Asentamientos Rurales de Reforma Agraria y las Reservas Extractivistas (Resex). Ambos se basan en la movilización social y en el enfrentamiento con los grandes propietarios rurales en defensa del acceso a la tierra y la conservación ambiental.

Los Asentamientos Rurales de Reforma Agraria se caracterizan como unidades de producción agrícola, creadas por medio de políticas gubernamentales que buscan el reordenamiento del uso de la tierra, en beneficio de trabajadores rurales sin o con poca tierra. Esos territorios ofrecen condiciones de vivienda y de producción a las familias beneficiarias. Son áreas adquiridas por el Incra - Instituto Nacional de Colonização e Roforma Agrária, por medio de la recaudación de tierras públicas o de la expropiación o compra de tierras privadas (Bergamasco \& Norder, 1996; Incra, 2018).

Las Reservas Extractivistas son una de las siete categorías de las Áreas Protegidas de Uso Sostenible, reguladas por el Sistema Nacional de Unidades de Conservação (SNUC), que buscan compatibilizar la conservación de los recursos naturales con el mantenimiento de los modos de vida de las poblaciones tradicionales que habitan esos territorios. Son áreas utilizadas por poblaciones tradicionales que tienen el extractivismo como principal medio de subsistencia, juntamente con la agricultura y la cría de animales pequeños (Brasil, 2000; Mma, 2018).

El concepto de Ordenación Territorial se deriva de la articulación de otros dos conceptos importantes: ordenación y territorio. El sustantivo ordenación se relaciona con la "organización de los elementos de un conjunto de acuerdo con una relación de orden, es decir, con la disposición (o arreglo) conveniente de los medios - según ciertas relaciones - para obtener los fines deseados" (Brasil, 2006, p. 184, traducción nuestra). Ya el concepto de territorio, aunque en diversas áreas del conocimiento tenga diferentes significados, en este trabajo, se definirá a partir de una perspectiva geográfica e integradora y de sus múltiples dimensiones: política, económica, cultural y ambiental. Así, territorio es un espacio socialmente ocupado y delimitado por relaciones de poder, siendo la fuente de recursos para la reproducción de la sociedad y el producto de las 
prácticas socioculturales (Raffestin, 1993; Santos, 1994; Haesbaert, 2004; Souza, 2008).

Este trabajo trata de analizar territorios destinados a la garantía de acceso a la tierra a miles de familias brasileñas, los Asentamientos Rurales y las Reservas Extractivistas. Eses territorios son fuentes de los recursos materiales necesarios para la reproducción de las familias que los habitan y el producto de las prácticas socioculturales desarrolladas por ellas.

Los Asentamientos Rurales son territorios destinados a la vivienda y a la producción agropecuaria de familias sin tierra, creados por el Estado para fines de reforma agraria. Esta puede ser entendida como el conjunto de medidas destinadas a promover una mejor distribución de la tierra, mediante modificaciones en el régimen de su posesión y uso, a fin de atender a los principios de la función social de la tierra (Brasil, 1964; Bergamasco \& Norder, 1996; Incra, 2018).

Vale la pena señalar, en ese sentido, que el proceso de formación del territorio brasileño, iniciado en el siglo XVI por los portugueses, tuvo como característica su marco colonial, basado en el trinomio latifundio, monocultivo y esclavitud. El proceso fue caracterizado por intereses estrictamente económicos, fundado en una estructura política colonial de explotación tanto de los recursos naturales como de mano de obra esclava, lo que resultó en una compleja estructura socioespacial, marcada por la concentración de la tierra en las manos de pocos propietarios y por el registro de luchas por el acceso a la tierra de una mayoría de trabajadores rurales (Bruno, 1995; Germani, 2006).

Las Reservas Extractivistas, así como los asentamientos rurales, son creadas por el Estado, pero como una modalidad de Área Protegida, a fin de compatibilizar la conservación de la naturaleza y el mantenimiento de las poblaciones tradicionales que habitan eses territorios. Las Áreas Protegidas son territorios con características naturales relevantes, que cumplen la función de resguardar la integridad de los ecosistemas, la biodiversidad y los servicios ambientales asociados a los mismos (Brasil, 2000; Mma, 2018). El modelo norteamericano de conservación de la naturaleza, difundido y adoptado mundialmente, parte del principio de que toda relación entre sociedad y naturaleza es degradadora, y que toda forma de vida social debe ser excluida de las áreas de protección de la naturaleza. Se trata, por lo tanto, de la concepción de naturaleza intacta, a partir de la predominancia de una visión estética y biológica de la misma (Diegues, 1998; 2000; 2008).

Tal concepción de conservación de la naturaleza, sin embargo, no se aplica a la realidad brasileña, ya que el mantenimiento de los recursos naturales en determinados territorios, sobre todo en la Amazonia, es el resultado de prácticas tradicionales de las comunidades que los habitan, como es el caso, por ejemplo, de las sociedades indígenas (Diegues, 1998; 2000; 2008). En este sentido, en Brasil, se crearon dos grupos de Áreas Protegidas: el de Protección Integral, pautado en el modelo norteamericano de naturaleza intacta, y el de Uso Sostenible, que tiene como objetivo conciliar la conservación de la biodiversidad y la garantía del derecho de permanencia y del modo de vida de las poblaciones tradicionales, que durante generaciones habitan esos territorios. Entre las categorías de Área Protegida de Uso Sostenible, se encuentran las Reservas Extractivistas, donde las comunidades que las habitan viven, básicamente, del extractivismo vegetal y animal, de la agricultura y crianza de animales pequeños (Brasil, 2000; Mma, 2018).

Se trata, entonces, de territorios habitados por poblaciones tradicionales, sea de agricultores o de extractivistas, donde el poder del Estado es determinante en la forma como se configura el uso y ocupación de los mismos. Por otro lado, tal configuración también ocurre en detrimento de las relaciones socioculturales en que tales grupos se encuentran insertados. Luego, al traer la temática de ordenación territorial se busca comprender cómo las políticas territoriales de acceso a la tierra, en la forma de Asentamientos Rurales y Reservas Extractivistas, impactan el medio ambiente en el contexto amazónico, sobre todo en el mantenimiento del bosque amazónico.

La discusión sobre los procesos de Ordenación Territorial se remite a la geografía francesa de la década de 1960, cuando fue utilizado como aparato teórico y técnico para la planificación y estímulo al desarrollo de Francia, buscando la articulación de diferentes políticas públicas sobre una base territorial (Moraes, 2005). El concepto surge de la necesidad de subdividir el territorio francés para fines de administración, teniendo en vista los límites naturales del territorio, así como 
características de orden económico y administrativo (Perez \& Chiquito, 2012). Además, la literatura también refuerza otras influencias en esa discusión, resaltando que la planificación sobre el territorio es producto de un período específico de la historia reciente, principalmente inglesa (Allmendinger e Haughton, 2009).

En ese contexto, la organización territorial se basaba en la atribución de usos y funciones al suelo, por medio de la delimitación y armonización de las diferentes funciones del territorio, como vivienda, industria, recreación, transporte, educación, naturaleza, agricultura y actividades culturales. Esta concepción, conocida como land-use planning, se fundamenta en instrumentos de planificación rígidos y detallados: instrumentos de zonificación regulatoria, de control de construcción y de implementación. Ellos desempeñan un papel determinante en la orientación del desarrollo e infraestructura física de los países (Kaiser et al, 1995; Albrechts, 2004; Davoudi e Strange, 2009; Alves, 2014).

El land-use planning se fundamentaba en ideales positivistas, expresando un carácter centralizador, inflexible y tecnicista, además de no priorizar las relaciones sociales intrínsecas al territorio. En esa perspectiva, la Ordenación Territorial, rechaza las relaciones sociales complejas en la construcción del espacio, cerrándose en el determinismo físico sin establecer interrelaciones con los demás elementos del territorio (Alves, 2014). Se constata que la predominancia del foco en los aspectos físicos del territorio hizo que "soluciones físicas" fuesen tomadas para problemas sociales o económicos (Albrechts, 2004).

Así, la principal crítica al concepto de land-use planning incide en su carácter rígido y pasivo que reduce la comprensión del territorio a un simple espacio de asignación de objetos, desconsiderando las personas que lo habitan. Las críticas al concepto apuntan hacia una perspectiva de Ordenación Territorial más abierta y flexible, a fin de responder de forma más rápida y adecuada a los cambios sociales y económicos (Alves, 2014). El geógrafo Rogerio Haesbaert también contribuyó con la discusión al afirmar que el territorio pasa, de esa forma, a ser entendido a partir de una perspectiva integradora, teniendo en cuenta aspectos políticos, económicos, naturales y culturales que se conjugan de formas diferenciadas en cada local. En consecuencia, la Ordenación Territorial y la planificación y/o las políticas que acompañan el territorio siguieron rumbos similares (Haesbaert, 2006).

Estas nuevas perspectivas respecto a la Ordenación Territorial apuntan para el abordaje conocido como strategic spatial planning, establecido, principalmente, a partir de 1990. Si antes la comprensión del territorio se basaba en escalas macroanalíticas y en la centralización del poder del Estado, rígido e inflexible, a partir de entonces las personas pasan a adquirir papel central en tal discusión (Salet \& Falud, 2000; Healey, 2004; Albrechts, 2004; Alves, 2014). Así, strategic spatial planning es conceptuado como "a public-sector-led sociospatial process through which a vision, actions, and means for implementation are produced that shape and frame what a place is and may become” (Albrechts, 2004, p. 747). Según el autor, tal concepción abarca un conjunto de conceptos, procedimientos y herramientas que deben adaptarse a cada situación. Por lo tanto, ese abordaje se refiere a una forma sistemática de manejar los cambios y de crear el mejor escenario futuro para el territorio; busca actuación integrada a largo plazo, a través de un sistema continuo de toma de decisiones y monitoreo, basadas en estructuras de gobernanza multinivel. El strategic spatial planning también incorpora la cuestión ambiental, a partir de una visión crítica del medio ambiente que busca determinar fuerzas y debilidades en el contexto de oportunidades y amenazas.

Los cambios conceptuales y prácticos acerca de la Ordenación Territorial apuntan hacia una perspectiva cada vez más flexible, multidimensional y participativa, sobre todo en lo que se refiere a la relación intrínseca entre Estado y Territorio. Las personas pasan a ser priorizadas en tal relación y, consecuentemente, el elemento cultural es incorporado. A este respecto, se destaca el concepto de planning cultures que trae en su principio la importancia de los aspectos culturales en la forma como el territorio se organiza y se desarrolla. Tal perspectiva admite que los sistemas de planificación sobre el territorio se caractericen no solo por sus estructuras organizativas e institucionales, sino también por sus aspectos culturales. Así, el concepto se caracteriza como el resultado de actitudes, reglas, patrones, creencias y valores acumulados y compartidos por un grupo social, y que influyen directamente en la forma en que el territorio es organizado (Friedmann, 2005; Knieling \& Othengrafen, 2009; 
Steinhauer, 2011; Alves, 2011). En ese entendido, las formas tradicionales de organización social de esos grupos influyen en la organización y gestión de los territorios en que habitan, sin embargo, sin excluir el papel del Estado en su organización y gestión.

Se observa, de este modo, la evolución conceptual y práctica acerca de la Ordenación Territorial, pasando de una concepción de carácter centralizador, inflexible y tecnicista, pautada en el concepto de land-use planning, hacia una perspectiva más abierta y flexible de planificación sobre los usos y las formas de ocupación del territorio, según sugerido por los enfoques de strategic spatial planning y planning cultures. La Tabla 1 sintetiza las principales características de las concepciones abordadas.

Tabla 1. Síntesis de las diferentes concepciones de Ordenación Territorial y sus principales puntos analíticos.

\begin{tabular}{|c|c|c|c|}
\hline Concepto & Definición & Métodos y Estrategias & Referencias \\
\hline $\begin{array}{c}\text { Land-use } \\
\text { planning }\end{array}$ & $\begin{array}{c}\text { Delimitación y armonización de las } \\
\text { diferentes funciones del territorio. }\end{array}$ & $\begin{array}{c}\text { Instrumentos de planificación rígidos y } \\
\text { detallados, ejemplos: instrumentos de } \\
\text { zonificación regulatoria, de control de } \\
\text { construcción y de implementación; } \\
\text { Carácter centralizador, inflexible y } \\
\text { tecnicista. }\end{array}$ & $\begin{array}{c}\text { Kaiser } \text { et al (1995); Albrechts } \\
\text { (2004); Davoudi \& Strange (2009); } \\
\text { Alves (2014). }\end{array}$ \\
\hline $\begin{array}{c}\text { Strategic spatial } \\
\text { planning }\end{array}$ & $\begin{array}{c}\text { Forma sistemática de manejar los } \\
\text { cambios y de crear el mejor } \\
\text { escenario futuro para el territorio. }\end{array}$ & $\begin{array}{c}\text { Carácter integrador, abierto y flexible; } \\
\text { Sistema de gobernanza participativo y } \\
\text { multinivel. }\end{array}$ & $\begin{array}{c}\text { Salet \& Falud, 2000; Albrechts } \\
(2004) ; \text { Healey, 2004; Alves (2014). }\end{array}$ \\
\hline $\begin{array}{c}\text { Resultado de actitudes, reglas, } \\
\text { patrones, creencias y valores } \\
\text { cultures }\end{array}$ & $\begin{array}{c}\text { Instrumentos de planificación y } \\
\text { gestión comunitarios; } \\
\text { que influyen directamente en la } \\
\text { forma en que se organiza el } \\
\text { territorio. }\end{array}$ & $\begin{array}{c}\text { Sistema de gobernanza participativo y } \\
\text { multinivel. }\end{array}$ & $\begin{array}{c}\text { Freadman (2005); Allmendinger \& } \\
\text { Haughton (2009), Knieling e } \\
\text { Othengafen (2009); Steinhauer } \\
\text { (2011), Alves (2014). }\end{array}$ \\
\hline
\end{tabular}

Fuente: Elaboración propia.

El rescate teórico-conceptual referente al concepto de Ordenación Territorial refuerza la necesidad de alternativas de planificación y gestión que sean coherentes con la singularidad ambiental y sociocultural de los territorios en que se busca intervenir. Sin embargo, en el contexto de la Amazonia brasileña, lo que se observó, sobre todo entre 1964 y 1984 , fue la implementación de estrategias territoriales que expresaron un carácter centralizador del Estado, tanto en el delineamiento como en la implantación de las mismas, con foco único y exclusivo en el desarrollo económico, pautado en los presupuestos del crecimiento, progreso, ampliación e incremento, fuertemente difundidos en los años 60 y 70 (Hagen, 1967; Perroux, 1967). En ese período, la Ordenación Territorial fue determinada, principalmente, por la reestructuración de la infraestructura física del territorio nacional, buscando la integración económica de la Amazonia, con inversión masiva en la ampliación del sistema de transporte por carretera y de telecomunicaciones, así como en la creación de grandes proyectos agropecuarios, forestales y de colonización (Becker, 2001; 2005).

En ese sentido, se verifica que los modelos y formas de apropiación del territorio amazónico implementados por el Estado fueron marcados, en gran medida, por los presupuestos del land-use planning, los cuales reducen la comprensión del territorio a un espacio de asignación de objetos, desconsiderando sus aspectos socioculturales y ambientales. De ese modo, se constata que en ese período la intensificación del proceso de ocupación de la Amazonia, subsidiado y centralizado por el Estado, fue pautado en macroestrategias de dominación y control, con foco en la reestructuración física del territorio, a fin de crear infraestructuras necesarias para el desarrollo económico de la región, sin llevar en cuenta sus singularidades ambientales y sociales. Las tensiones sociales y ambientales intensificadas por ese modelo de ocupación del territorio llevaron, a partir de la redemocratización del país, al surgimiento de demandas por nuevas formas de Ordenación Territorial basadas en instrumentos 
de planificación y gestión más abiertos y flexibles con el objetivo de integrar los diferentes actores sociales, las esferas de actuación, las escalas de gobernanza y la dimensión ambiental. Así, la Amazonía pasa a ser escenario de nuevas políticas, proyectos, planes y acciones en diferentes sectores, segmentos y escalas de actuación que sugieren la incorporación de los preceptos del strategic spatial planning en la organización de aquel territorio.

Como ejemplo de estas nuevas estrategias territoriales, se verificó la creación, en 1988, del Programa de Defesa do Complexo de Ecossistemas da Amazônia Legal, denominado Programa Nossa Natureza, que tenía como finalidad establecer condiciones para la utilización y la preservación del medio ambiente y de los derechos de los recursos naturales renovables en la Amazonía Legal (Gutberlet, 2002).

Se inició también, en el mismo año, el proyecto de Zoneamento Ecológico-Econômico da Amazônia - ZEE que incorporó en sus objetivos cuestiones de cuño social y cultural, como la preocupación por proteger a las poblaciones tradicionales e incluso por promover la educación ambiental (Gutberlet, 2002). En ese contexto que se insertan los instrumentos de Ordenación Territorial relacionados a la garantía de acceso a la tierra, como el Programa Nacional de Reforma Agrária (Brasil, 1993), el Sistema Nacional de Unidades de Conservação (Brasil, 2000) y la Política Nacional de Gestão Territorial e Ambiental de Terras Indígenas (Brasil, 2012). El primero se relaciona con la creación de Asentamientos Rurales destinados a familias sin tierra, generalmente, por medio de la apertura de unidades agrícolas convencionales. El siguiente se refiere a la delimitación de Áreas de Protección Ambiental donde las Resex están insertas. Ya el tercer programa está relacionado con la demarcación y protección de las tierras indígenas, a fin de garantizar la diversidad étnica y cultural de esos pueblos. Todos esos instrumentos fueron creados como forma de mitigar los conflictos socioambientales derivados de la política de integración nacional y consolidación de la frontera económica del Norte del país (Brasil, 2006).

Aunque existan diferentes políticas e instrumentos de Ordenación Territorial relacionados con la garantía de acceso a la tierra, este trabajo tiene como centro de atención los Asentamientos Rurales de Reforma Agraria y las Reservas Extractivistas. Tal elección se derivó de la perspectiva de que el modelo de organización y movilización social para la creación de ambos instrumentos sigue la misma trayectoria, incluso, desde el punto de vista político e histórico en la lucha por la tierra. Es decir, son procesos que demandaron una intensa movilización social y enfrentamiento ante grandes propietarios rurales en defensa del cumplimiento de la función social de la tierra, sea por la productividad agrícola o por la protección ambiental y el mantenimiento de los modos de vida de las poblaciones tradicionales.

Existen en Brasil, 9128 Asentamientos Rurales de Reforma Agraria, que ocupan un área de 51619036 hectáreas y albergan 893228 familias (Cuadro 2). Del total de los asentamientos, $39 \%$ se encuentra en la Amazonia Legal, lo que corresponde a $8 \%$ de aquel territorio y a $81 \%$ del área total destinada a la reforma agraria en el país. Solo entre 2003 y 2014, se asentaron cerca de 217700 familias en la región de un total de aproximadamente 331,7 mil familias asentadas en Brasil, en el mismo período. Si se restringe este análisis, específicamente, al bioma amazónico, se verifica que $24 \%$ de los asentamientos se ubicam en el referido bioma, ocupando un área de aproximadamente $6,5 \%$ de éste y $67 \%$ del área reformada en el país (Ipam, 2016).

Por otro lado, hay 93 Reservas Extractivistas en Brasil, siendo 66 de ellas administradas en la esfera federal por el Instituto Chico Mendes de Conservação e Biodiversidade - ICMBio y 28 por la esfera estadual (Tabla 2). Las Resex federales ocupan cerca de 13,3 millones de hectáreas, siendo 85 \% de este total en el bioma amazónico, además de albergar a miles de familias (Icmbio, 2018). 
Tabla 2. Números y área (en hectáreas) de los Asentamientos Rurales y de las Reservas extractivistas en Brasil y en el bioma Amazonia.

\begin{tabular}{|c|c|c|c|c|c|}
\hline \multicolumn{3}{|c|}{ Asentamientos rurales } & \multicolumn{3}{|c|}{ Reservas Extractivistas* } \\
\hline Total & Área ocupada & $\mathrm{N}^{0}$ de familias & Total & Área ocupada & $\mathrm{N}^{0}$ de familias \\
\hline \multicolumn{6}{|c|}{ Brasil } \\
\hline 9.128 & 51.619 .036 & 893.228 & 66 & 13.375.261,08 & 53.240 \\
\hline \multicolumn{6}{|c|}{ Bioma Amazonia } \\
\hline 2.217 & 34.464 .312 & 447.341 & $33 * *$ & $11.414 .942,67$ & 18.564 \\
\hline
\end{tabular}

*Datos referentes a las Reservas Extractivistas federales.

** No se contabilizaron las reservas extractivas marinas que se encuentran en el territorio amazónico.

Fuente: Elaboración propia.

Es importante destacar que existen diferentes modalidades de Asentamientos Rurales, insertadas en diferentes categorías. Además de los Asentamientos Convencionales, conocidos como Projetos de Assentamentos (PA), basados en la individualización de parcelas agrícolas, actualmente, existen otras modalidades que atienden a las nuevas demandas ambientales, sobre todo de la Amazonia, por ejemplo, los Projetos de Assentamentos Agroextrativistas (PAE), los Projetos de Desenvolvimento Sustentável (PDS) y los Projetos de Assentamento Florestal (PAF). Todos ellos se caracterizan como Ambientalmente Diferenciados y son dirigidos a poblaciones tradicionales, como ribereños y comunidades extractivistas (Incra, 2018).

El Incra también ha creado y tiene registrado en su sistema de informaciones, llamado Sistema de Informações de Projetos da Reforma Agrária (SIPRA), los siguientes proyectos: Projetos de Colonização (PC), Projetos Integrados de Colonização (PIC), Projetos de Assentamento Rápido (PAR), Projetos de Colonização Particular (PAP), Projetos de Assentamento Dirigido (PAD) y Projetos de Assentamento Conjunto (PAC). Todas esas modalidades desde la década de 1990 no son más creadas (Incra, 2018).

Se constata que, en el bioma amazónico, los Asentamientos Rurales de Reforma Agraria y las Reservas Extractivas ocupan cerca de 46 millones de hectáreas, lo que corresponde a aproximadamente $10 \%$ de este territorio y $6 \%$ del territorio nacional. Esos números expresan la importancia de la Amazonía, tanto por su singularidad ambiental como por el papel que representa en la reforma agraria del país. Sin embargo, el patrón de uso y ocupación delineado en la implementación de esos territorios presenta diferentes impactos al medio ambiente, sobre todo en el contexto amazónico. Si por un lado, las Reservas Extractivistas se presentan como un modelo sostenible de utilización del bosque por las familias que residen en ella (Fearnside, 1989; Almeida, 2012), por otro, los Asentamientos Rurales están directamente relacionados al proceso de deforestación, ya que poseen proyectos orientados a la formación de nuevos agricultores que reproducen el modelo predominante en la agropecuaria regional (Le Tourneau \& Bursztyn, 2010; Ipam, 2016).

Este artículo tiene como objetivo analizar cómo los Asentamientos Rurales y las Reservas Extractivistas y sus diferentes formas de uso y ocupación del territorio interfieren en el mantenimiento del bosque amazónico. Se buscó articular conceptualmente elementos asociados al significado de Ordenación Territorial con la dimensión empírica derivada de los modelos y formas de apropiación del territorio, en el contexto de políticas públicas y de los procesos de intervención del Estado en la región Amazónica. De forma específica, se presenta las diferentes formas de organización territorial en los Asentamientos Rurales de Reforma Agraria y en las Reservas Extractivistas y sus distintos impactos en el medio ambiente.

\section{Materiales Y Métodos}

Este es un estudio de naturaleza cualitativa, basado en revisión de la literatura, que buscó articular conceptualmente 
elementos asociados a la Ordenación Territorial con la dimensión empírica derivada de los modelos y formas de apropiación del territorio conducidos por el Estado, teniendo como base la implementación de los Asentamientos Rurales de Reforma Agraria y de las Reservas Extractivistas, en el estado del Acre, en la Amazonia brasileña y sus distintos impactos en el mantenimiento del bosque amazónico (Figura 1). La revisión de la literatura es el proceso de búsqueda, análisis y descripción de un área particular del conocimiento en busca de respuestas a una pregunta específica (Quivy \& Campenhoudt, 1998). En este estudio se priorizó la búsqueda de artículos científicos, disertaciones, tesis, libros y documentos oficiales, con el objetivo de seleccionar textos con enfoques conceptuales y metodológicos diversificados del fenómeno investigado, buscando resaltar sus convergencias, divergencias y complementariedades.

Fueron seleccionados para el estudio, tres reservas extractivistas (Resex Alto Juruá, Resex Chico Mendes y Resex Cazumbá-Iracema), de los asentamientos convencionales de reforma agraria (PAD Boa Esperança y PA Gal Moreno Maia) y de los asentamientos ambientalmente diferenciados (PAE Cruzeiro do Vale y PAE Chico Mendes).

Figura 1. Asentamientos Rurales y Reservas Extractivistas en el Estado de Acre, Brasil.

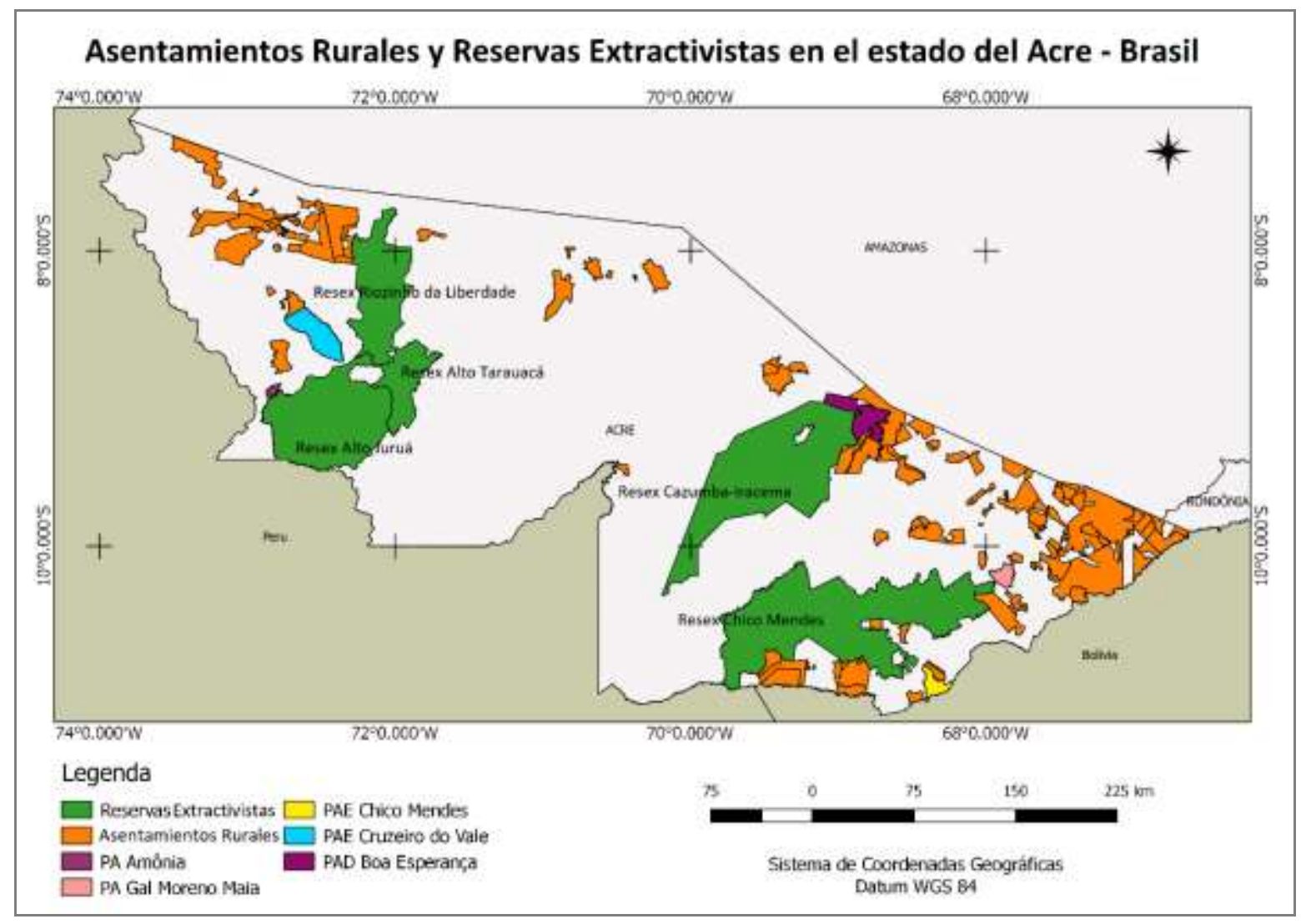

Fuente: Elaboración propia.

Asociado a la revisión de la literatura, se utilizó la observación cualitativa de imágenes de satélite de Google Earth. Se seleccionaron imágenes del año de creación y del año 2018 para cada uno de los territorios analizados, con el fin de observar los cambios que se han producido en el uso y ocupación de estos territorios desde su implementación hasta la actualidad. Se utilizó también datos secundarios de intuiciones estatales, como ICMBIo, INCRA, MMA y IPAM, para contextualizar el escenario de las Reservas Extractivistas y de los Asentamientos Rurales de Reforma Agraria en la Amazonia y, más específicamente, en el estado del Acre. 


\section{Resultados Y Discusiones}

Aunque los Asentamientos Rurales y las Reservas Extractivistas son instrumentos de Ordenación Territorial destinados a garanterizar el acceso a la tierra, se constató que la implementación de los mismos impacta de distintas maneras el medio ambiente, puesto que los patrones de uso y ocupación de eses territorios siguen lógicas diferentes. La organización de los territorios donde se encuentran los Asentamientos Rurales sigue un modelo basado en la delimitación de parcelas agrícolas, la mayoría de las veces, realizado de forma homogénea, por medio de los llamados "quadrados-burros" (Figura 2) (Ferreira Neto et al., 2010; Ferreira e Ferreira Neto, 2017). Es decir, la delimitación de las áreas de asentamientos rurales, en la mayoría de las veces, desconsidera o no prioriza aspectos físicos, tales como tipos de suelos, relieve, hidrografía y aptitud agrícola. El modelo de parcelamiento de las unidades familiares de producción agrícola adoptado por el Incra privilegia el tamaño de las parcelas y no su capacidad productiva, ocasionando, de esta forma, una desigual distribución de los recursos a ser usufructuados por las familias asentadas (Ferreira Neto et al., 2010; Ferreira e Ferreira Neto, 2017).

Figura 2. Ejemplos de parcelamientos de asentamientos de reforma agraria.

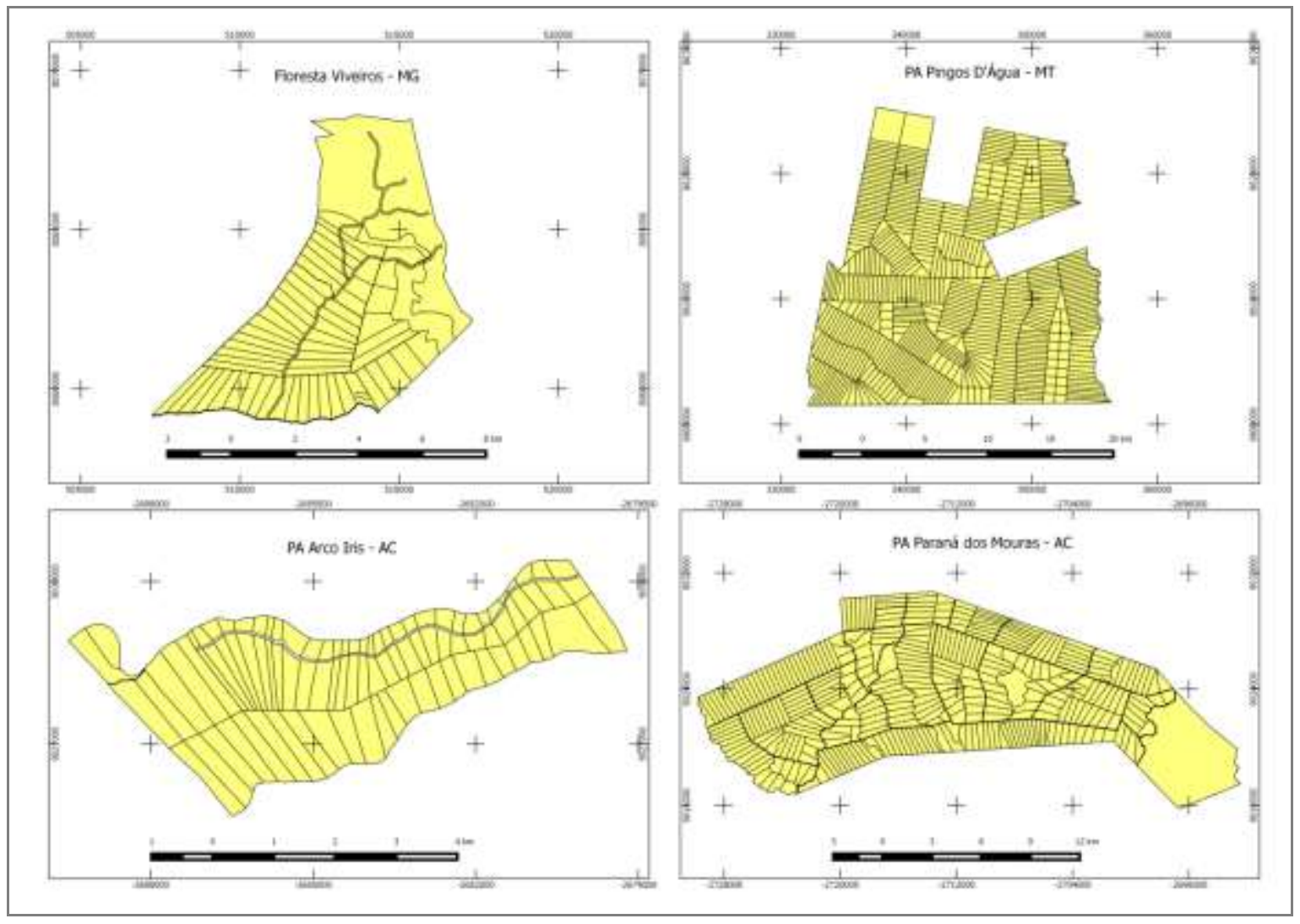

Fuente: Ferreira (2015).

Los asentamientos están asociados, de ese modo, al proceso de deforestación para el desarrollo de actividades agropecuarias, expresado en el modelo denominado "espina de pez" o fish-bone, que es determinado por la creación de lotes agrícolas, generalmente rectangulares, establecidos a lo largo de vías vecinales que se originan de una vía principal (Metzger, 2001; Arima et al., 2015; Leal, 2016). La “espina de pez” es considerada uno de los principales patrones de uso y ocupación en la Amazonia brasileña y fue el modelo adoptado por el Incra en la creación de los proyectos de colonización, y que se mantuvo en los Proyectos de Asentamientos de Reforma Agraria, a partir de 1985. La tasa de deforestación es normalmente rápida en esos territorios. En los primeros años de creación, la deforestación varía entre 2 y 3 hectáreas por familia y por lote, resultando en más de $70 \%$ de la deforestación del lote en los primeros 20 años. Tal constatación evidencia el incumplimiento del Código 
Forestal Brasileño que prevé el mantenimiento de $80 \%$ de la propiedad con vegetación nativa en aquella región (Metzger, 2001).

Las Figuras 3 y 4, ejemplifican el patrón de uso y ocupación "espina de pez" en la creación de Asentamientos Rurales de Reforma Agraria en el estado de Acre, Brasil. En la Figura 3, se puede observar imágenes de satélite del Projeto de Assentamento Dirigido (PAD) Boa Esperança en 1984 y en 2018. Es importante resaltar que ese asentamiento fue creado en 1976, sin embargo, la primera imagen del área, disponible en Google Earth, data de 1984. Las imágenes constatan el intenso proceso de deforestación pautado en el patrón de uso y ocupación fish-bone. Se verifica un patrón similar en el entorno del asentamiento, al Norte, Nordeste y Este.

Figura 3. PAD Boa Esperança, AC, Brasil, 1984 y 2018.
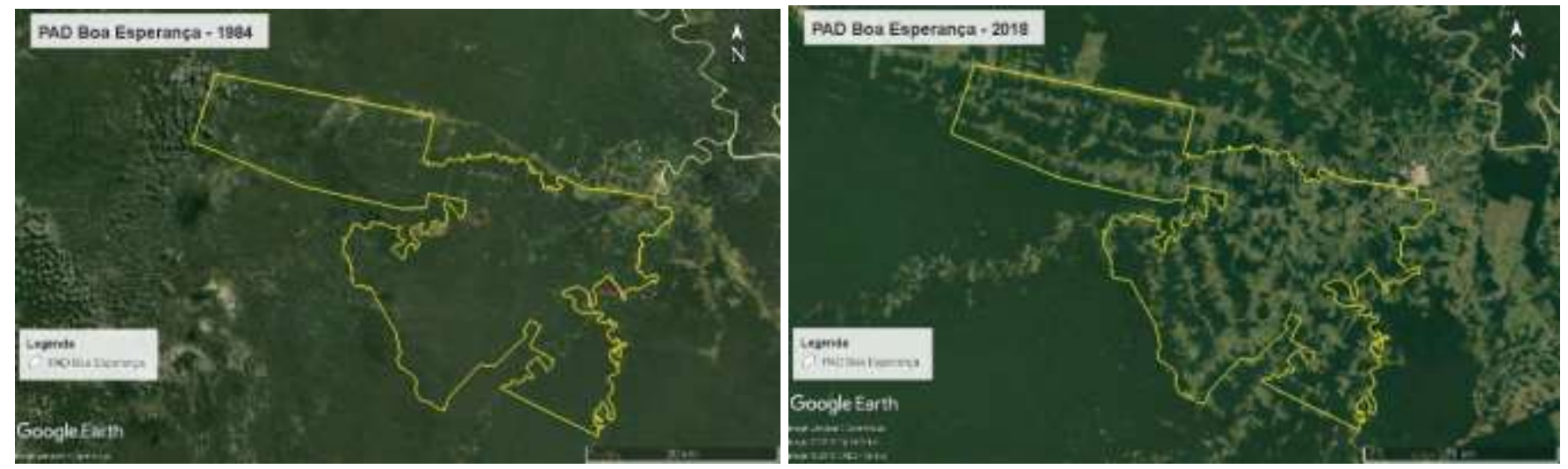

Fuente: Elaboración propia a partir de imágenes del Google Earth.

Figura 4. PA Gal Moreno Maia, AC, Brasil, 1996 y 2018.
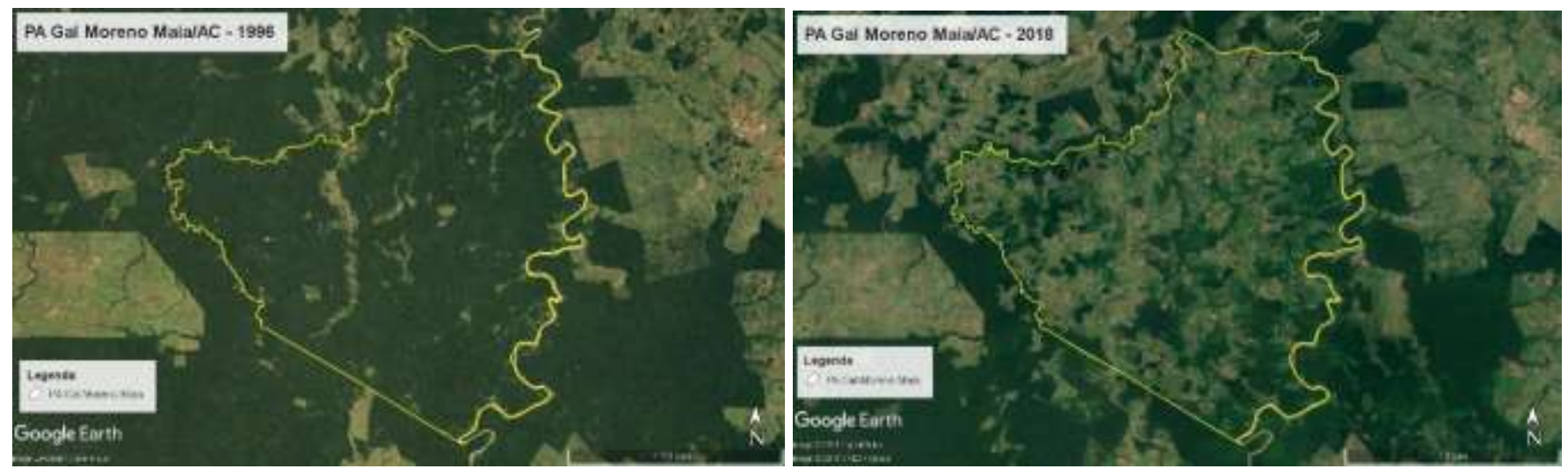

Fuente: Elaboración propia a partir de imágenes del Google Earth.

La Figura 4, presenta imágenes de satélite del Projeto de Asentamiento (PA) Gal Moreno Maia en 1996, año de su creación, y en 2018. En ese asentamiento, así como en el PAD Boa Esperança, también se observa la intensiva deforestación del área basada en el patrón fish-bone, quedando pocos fragmentos de bosque. Las áreas circundantes también siguen el mismo patrón de uso y ocupación. La literatura señala que los Asentamientos Rurales de Reforma Agraria han contribuido de forma expresiva en la deforestación de la Amazonía (Metzger, 2001; Le Tourneau e Bursztyn, 2010; Ipam, 2016). Así, la polémica acerca de la importancia de los avances sociales que los asentamientos representan y de los impactos ambientales resultantes de su creación llama la atención sobre la dificultad de implementación de asentamientos sostenibles desde el punto de vista social, ambiental y económico (Le Tourneau e Bursztyn, 2010; Ipam, 2016). Entre 2011 y 2014, los Asentamientos Rurales contribuyeron, en media, con un tercio en la deforestación amazónica, lo que los han puesto en la condición de principales 
responsables por el proceso de conversión forestal en la región. Además, a pesar de los asentamientos haber presentado una reducción en términos absolutos del área deforestada, ellos también presentaron tendencia de aumento relativo en la contribución media histórica de la deforestación total de la Amazonía, pasando de 24\% al final de la última década (2003 2010) para 29,2\% en los últimos cuatro años (2011-2014) (Ipam, 2016).

Los Asentamientos Convencionales son los que más contribuyen para la deforestación en la Amazonia. Esta modalidad agrega $82 \%$ de la deforestación acumulada dentro de los asentamientos de la región. Por otro lado, los Asentamientos Ambientalmente Diferenciados han aumentado en la Amazonía y son los que menos contribuyen para la conversión de bosques en otros usos de la tierra, contabilizando 7\% de la deforestación que ocurrió dentro de los asentamientos de la región (Ipam, 2016). Así, la inversión en la consolidación de los Asentamientos Ambientalmente Diferenciados puede representar avances en la reducción de la deforestación dentro de los asentamientos y en la Amazonía de modo general.

La Figura 5 representa el Projeto de Assentamento Agroextrativista (PAE) Cruzeiro do Vale en el año de su creación, 1999, y en 2018. Se verifica que, aunque han pasado casi 20 años de su creación, el área del bosque permanece básicamente intacta, lo que demuestra que el patrón de uso y ocupación en esta modalidad de Asentamiento Ambientalmente Diferenciado no sigue el mismo modelo de los Asentamientos Convencionales, aproximándose, de ese modo, al modelo verificado en las Reservas Extractivistas. Lo mismo se verifica en el PAE Chico Mendes (Figura 6), donde se percibe algunas manchas de deforestación; sin embargo, son poco significativas cuando comparadas a los asentamientos convencionales. Por otro lado, en la región al entorno del asentamiento la deforestación es intensa, como puede observarse en la Figura 6.

Figura 5. PAE Cruzeiro do Vale, AC, Brasil, 1999 y 2018.
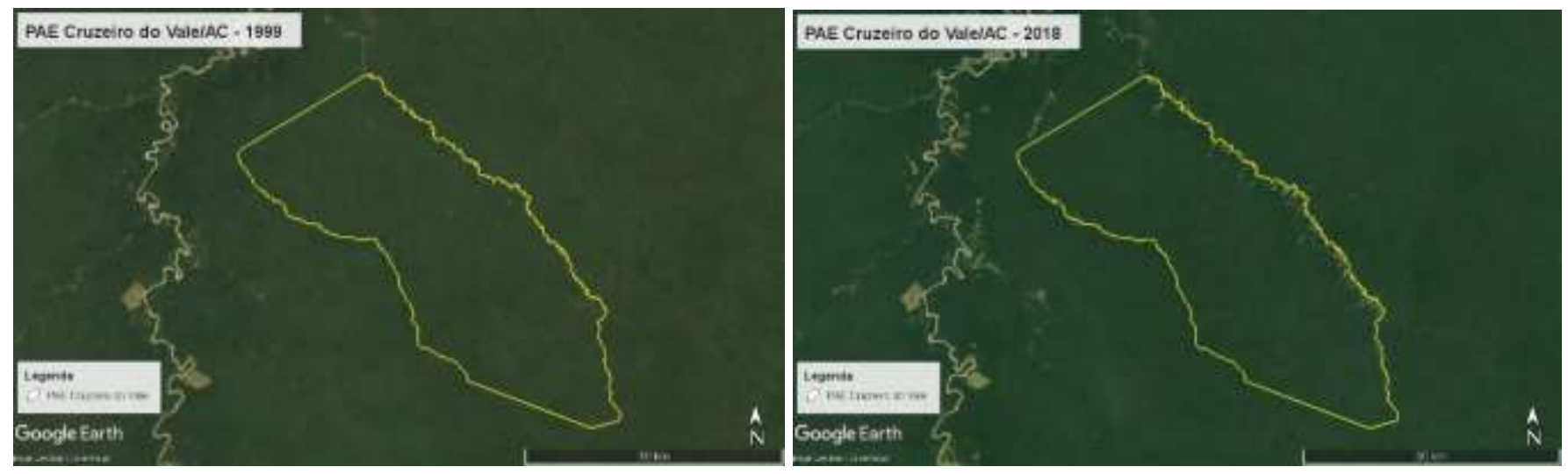

Fuente: Elaboración propia a partir de imágenes del Google Earth.

Figura 6. PAE Chico Mendes, AC, Brasil, 1988 y 2018.
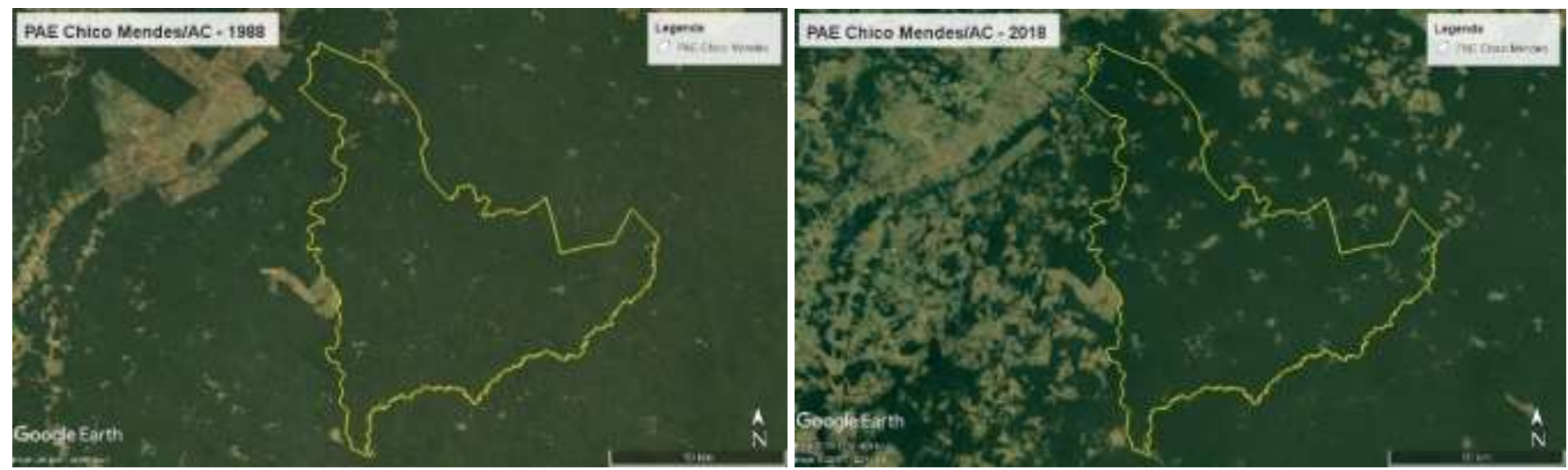

Fuente: Elaboración propia a partir de imágenes del Google Earth. 
Como se ha mencionado, la delimitación de las Reservas Extractivistas se basa en las formas tradicionales de ocupación del territorio por las poblaciones que allí habitan desde hace generaciones (Diegues, 1998; 2000; 2008; Almeida, 2012). La primera Reserva Extractivista creada en Brasil fue la Resex Alto Juruá, en el estado de Acre, en 1990, fruto de la lucha de los seringueiros por el mantenimiento de sus territorios y modos de vida tradicionales (Almeida, 1993; Cunha e Loureiro, 2009). El modo de vida en las colocaciones forestales es la base del concepto de Reserva Extractivista. La colocación es una organización social y un sistema económico que se caracteriza por el uso diversificado de territorios forestales por una red vecinal familiar vinculadas o conectadas que comparten ambientes en común. El reconocimiento institucional de ese modelo como base de las Reservas Extractivistas demuestra su potencial de organización colectiva de uso del bosque, que concilia formas de uso y ocupación poco agresivas con la naturaleza y que pueden proporcionar calidad de vida a sus habitantes (Almeida, 2012).

Las Figuras 7, 8 y 9 ilustran el patrón de uso y ocupación del territorio en tres Reservas Extractivistas en el estado de Acre, Brasil. En la Figura 6 se observa la Resex Alto Juruá, en el año de su creación, en 1990, y en 2018, respectivamente. Se constata que el bosque permaneció básicamente intacto, siendo posible observar la intensificación de su uso a lo largo de los dos principales ríos que cortan la Resex: el Juruá, en el Oeste, y el Tejo, al Norte. En la Figura 8 se observa la Resex Chico Mendes, en 1990, su año de creación, y en 2018. Se verifica que la cobertura forestal se presenta prácticamente inalterada en el área de la Resex, mientras que, al Sur, Este, Norte y Nordeste de ese territorio se constata un intenso proceso de retirada del bosque, basado en el patrón fish-bone. Lo mismo se observa en la Resex Cazumbá-Iracema (Figura 9), es decir, el bosque permanece fundamentalmente intacto en el área de la Resex, desde su año de creación, en 2002, hasta los días actuales, mientras que al Este y Nordeste del área también se nota el avance de la frontera agropecuaria.

Figura 7. Resex Alto Juruá, AC, Brasil, 1990 y 2018.

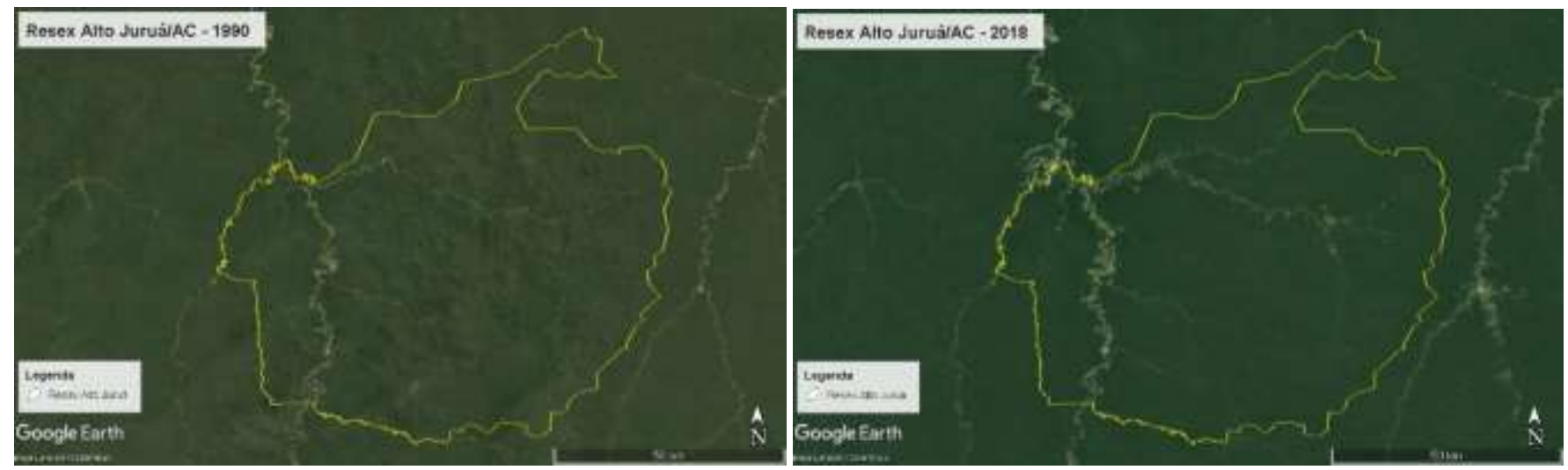

Fuente: Elaboración propia a partir de imágenes del Google Earth. 
Figura 8. Resex Chico Mendes, AC, Brasil, 1990 y 2018.

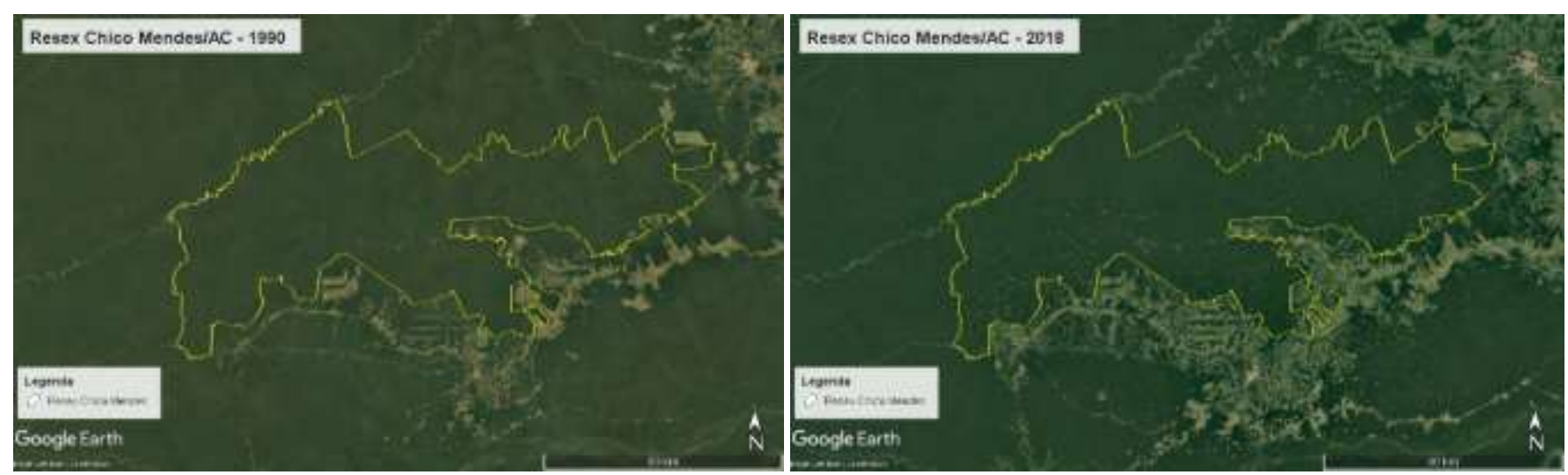

Fuente: Elaboración propia a partir de imágenes del Google Earth.

Figura 9. Resex Cazumbá-Iracema, AC, Brasil, 2002 e 2018.

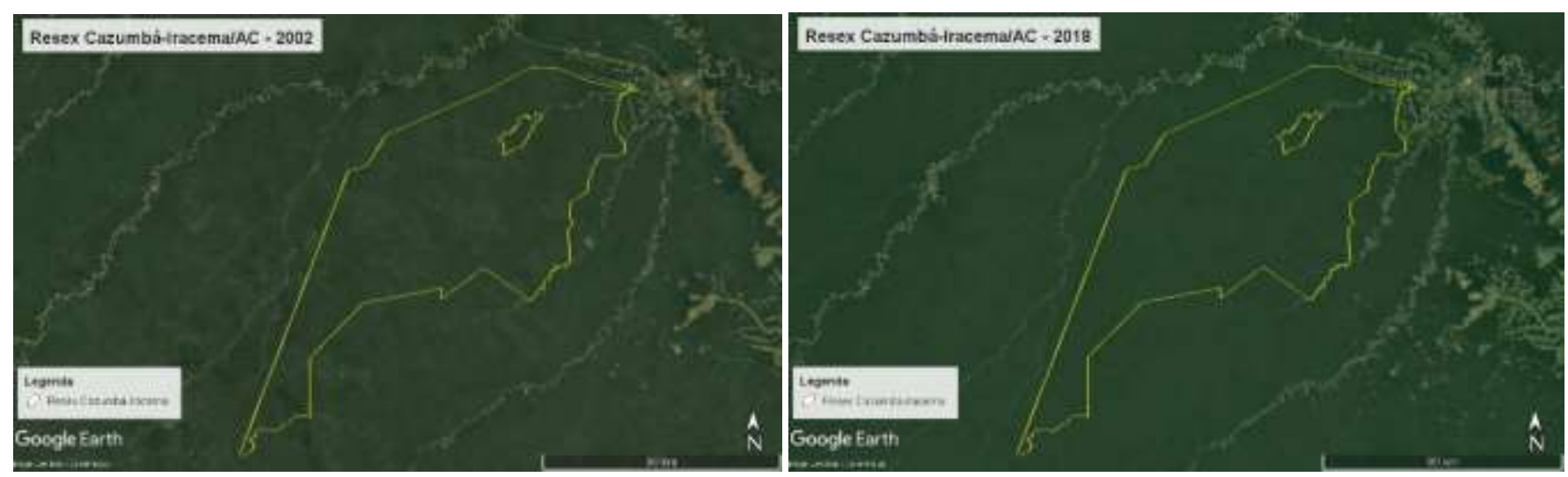

Fuente: Elaboración propia a partir de imágenes del Google Earth.

En fin, el análisis de las principales formas de acceso a la tierra en la Amazonia brasileña muestra que la dinámica de uso y ocupación de esos territorios sigue lógicas distintas y, consecuentemente, produce diferentes impactos en el medio ambiente. En este sentido, la creación de Asentamientos Rurales está directamente asociada a la retirada de la cobertura forestal para implantación de actividades agropecuarias convencionales, mientras que las Reservas Extractivistas cumplen la función de mantenimiento del bosque y de los modos de vida de las familias que habitan esos territorios.

\section{Consideraciones Finales}

El análisis propuesto demuestra que los diferentes patrones de uso y ocupación del territorio en los Asentamientos Rurales y en las Reservas Extractivistas interfieren de manera distinta en la dinámica ambiental de la Amazonia. Mientras las Reservas Extractivistas se presentan como una forma de compatibilización entre la conservación del bosque y el mantenimiento de los modos de vida de las poblaciones tradicionales, los Asentamientos Rurales, sobre todo los Convencionales, contribuyen para la conversión del bosque en otros usos, como la agricultura y la ganadería.

Por lo tanto, se puede concluir que las Reservas Extractivistas se destacan como un modelo de organización del territorio que está en sintonía con las singularidades ambientales y socioculturales de la Amazonia, pues privilegia formas tradicionales de uso y ocupación del territorio, que vienen contribuyendo para el mantenimiento de las familias que allí residen, sino también de la cobertura forestal. Por otro lado, se observa la incompatibilidad del modelo de ordenación de los Asentamientos Rurales Convencionales con la realidad ambiental y sociocultural de la Amazonia, que tradicionalmente 
mantuvo una relación muy cerca con el bosque, pautada en el extractivismo. Es importante destacar que la intención no es colocar los Asentamientos Rurales como "villanos" y las Reservas Extractivistas como los "buenos". La intención es problematizar los impactos causados por las diferentes formas de uso y ocupación del área en estos territorios y, así, reforzar la necesidad de planificación y gestión por parte del Estado, que tenga en vista las singularidades de la realidad amazónica.

En este sentido, la creación de Asentamientos Rurales Convencionales en la Amazonia debe ser repensada de forma a compatibilizar el desarrollo socioeconómico de la región, la mejora de la calidad de vida de su población y la gestión responsable de los recursos naturales. La inversión en la consolidación de los Asentamientos Ambientalmente Diferenciados representa una alternativa para la reducción de la deforestación, además de presentarse como modelo acorde y adaptado a la realidad amazónica. Así, las Reservas Extractivistas y los Asentamientos Rurales Ambientalmente Diferenciados representan alternativas capaces de conciliar la garantía de acceso a la tierra y la preservación del bosque amazónico brasileño.

Por otro lado, se necesitan más inversiones en investigaciones cuantitativas y cualitativas que articulen variables socioeconómicas, culturales y ambientales para comprender los impactos de los modelos de ordenamiento territorial implementados en asentamientos rurales y reservas extractivas sobre el mantenimiento del bosque amazónico.

\section{Agradecimientos}

Este trabajo se realizó con el apoyo de la Coordenação de Aperfeiçoamento de Pessoal de Nível Superior Brasil (CAPES) - Código de Financiamiento 001.

\section{Referências}

Allmendinger, P. (2009). Critical reflections on spatial planning. Environment and Planning A, 41(11), 2544-2549. https://doi.org/10.1068/a42227

Almeida, M. W. (1993). A Criação da Reserva Extrativista do Alto Juruá: conflitos e alternativas para conservação. Universidade Estadual de Campinas, Departamento de Antropologia Terceira Versão.

Almeida, M. W. B. (2012). As colocações: forma social, sistema tecnológico, unidade de recursos naturais. Mediações-Revista de Ciências Sociais, 17(1), 121-152. http://dx.doi.org/10.5433/2176-6665.2012v17n1p121

Alves, L. D. S. F. (2014). Culturas de ordenamento territorial: conceituações e perspectivas histórico analíticas. Mercator (Fortaleza), 13, 63-73. DOI: 10.4215/RM2014.1303. 0005.

Albrechts, L. (2004). Strategic (spatial) planning reexamined. Environment and Planning B: Planning and design, 31(5), 743-758. DOI: 10.1068/b3065 Ângelo, H., \& Sá, S. P. P. D. (2007). O desflorestamento na Amazônia Brasileira. Ciência Florestal, 17(3), 217-227. https://doi.org/10.5902/198050981953

Arima, E. Y., Barreto, P., Araújo, E., \& Soares-Filho, B. (2014). Public policies can reduce tropical deforestation: Lessons and challenges from Brazil. Land use policy, 41, 465-473. http://dx.doi.org/10.1016/j.landusepol.2014.06.026

Becker, B. K. (2010). Revisão das políticas de ocupação da Amazônia: é possível identificar modelos para projetar cenários? Parcerias estratégicas, 6(12), 135-159.

Becker, B. K. (2005). Geopolítica da Amazônia. Estudos Avançados, 19(53), 71-86. http://dx.doi.org/10.1590/S0103-40142005000100005.

Bergamasco, S. M., \& Norder, L. A. C. (1996). O que são assentamentos rurais (Vol. 1). São Paulo: Brasiliense.

Brasil. Lei n. 4.504, de 30 de novembro de 1964. Dispõe sobre o Estatuto da Terra e dá outras providências. Brasília, DF: Presidência da República, [1964]. http://www.planalto.gov.br/ccivil_03/LEIS/L4504.htm.

Brasil. Lei n. 9.985, de 18 de julho de 2000. Vetos da presidência da República ao PL aprovado pelo congresso Nacional. Sistema Nacional de Unidades de conservação. Brasília, DF: Presidência da República, [2000]. http://www.planalto.gov.br/ccivil_03/leis/19985.htm.

Brasil (2006). Documento base para a definição da Política Nacional de Ordenamento Territorial - PNOT (Versão Preliminar). Ministério da Integração Nacional, Secretaria de Políticas de Desenvolvimento Regional (SDR). - Brasília: MI, 2006. 260 p. http://www.mi.gov.br/c/document_library/get_file?uuid=45546192-e711-497a-8323-07244ee574ce\&groupId=24915.

Brasil. Decreto No 7.747, De 5 de junho de 2012. Institui a Política Nacional de Gestão Territorial e Ambiental de Terras Indígenas - PNGATI, e dá outras providências [2012]. http://www.planalto.gov.br/ccivil_03/_ato2011-2014/2012/decreto/d7747.htm

Bruno, R. (1995). O Estatuto da Terra: entre a conciliação e o confronto. Estudos sociedade e Agricultura. http://168.96.200.17/ar/libros/brasil/cpda/estudos/cinco/regina5.htm 
Carrero, G. C., Fearnside, P. M., do Valle, D. R., \& de Souza Alves, C. (2020). Deforestation Trajectories on a Development Frontier in the Brazilian Amazon: 35 Years of Settlement Colonization, Policy and Economic Shifts, and Land Accumulation. Environmental management, 66(6), 966-984.

Cunha, C. C., \& Loureiro, C. F. B. (2009). Reservas extrativistas: limites e contradições de uma territorialidade seringueira. Theomai, (20), 169-185. http://www.revista-theomai.unq.edu.ar/numero20/ArtCunha.pdf.

Davoudi, S., \& Strange, I. (Eds.). (2008). Conceptions of space and place in strategic spatial planning (Vol. 17). Routledge.

Diegues, A. C. S. (2008) O mito moderno da natureza intocada. São Paulo: Hucitec, Nupaub-USP/CEC.

Diegues, A. C. (1998). Recycled rainforest myths. Terra Nova's Nature $\quad$ and http://nupaub.fflch.usp.br/sites/nupaub.fflch.usp.br/files/terranova.pdf.

Diegues, A. C. (2000). Saberes tradicionais e etnoconservação. Comunidades tradicionais e manejo dos recursos naturais da Mata Atlântica, Hucitec, São Paulo, SP, Brazil, pp9-22.

Ferrante, L., Andrade, M. B., \& Fearnside, P. M. (2021). Land grabbing on Brazil's Highway BR-319 as a spearhead for Amazonian deforestation. Land Use Policy, 108, 105559.

Ferreira neto, J.A. et al (2010). O uso do Aplicativo SOTER e da Cartografia Social na Organização Territorial em Projetos de Reforma Agrária. In: Ferreira Neto, J. A., Sousa, D. N. de, Milagres, C. S. F. (Coord.) Recursos naturais, Sistemas de Informação Geográfica e Processos Sociais, Suprema, Visconde do Rio Branco, $M G$, pp238-248.

Ferreira, F. M. (2015) Aptidão agrícola das terras como função de otimização para o ordenamento territorial e planejamento ambiental: uma análise do SOTER-PA. Dissertação (Mestrado em Extensão Rural). Minas Gerais: Universidade Federal de Viçosa.

Ferreira, F. M.; Ferreira Neto, J. A (2017). O SOTER-PA como alternativa para o ordenamento territorial dos assentamentos rurais de reforma agrária. Espacios (Caracas), 38(13), 12-21. https://www.revistaespacios.com/a17v38n13/17381312.html.

Friedmann, J. (2005). Globalization and the emerging culture of planning. Progress in Planning, 64(3), 183-234. doi:10.1016/j.progress.2005.05.001

Germani, G. I. (2006). Condições históricas e sociais que regulam o acesso a terra no espaço agrário brasileiro. GeoTextos, 2(2). http://www.geografar.ufba.br/site/arquivos/biblioteca/publicacoes/9a648763dc58f84a08aad80e4672b8fe.pdf

Gutberlet, J. (2002). Zoneamento da Amazônia: uma visão crítica. Estudos Avançados, 16, 157-174. https://doi.org/10.1590/S0103-40142002000300013

HAESBAERT, R. (2004) O Mito da desterritorialização: do fim dos territórios à multiterritorialidade. Rio de Janeiro: Bertrand.

Haesbaert, R. (2006). Ordenamento Territorial. Boletim Goiano de Geografia. Instituto de Estudos Sócio-Ambientais, 26, (1), 117-124. https://revistas.ufg.br/bgg/article/view/3572.

Hagen, E. (1967). O processo de mudança. In: Durand, J. C. G. (Coord.) Sociologia do Desenvolvimento (pp. 27-40). Rio de Janeiro: Zahar Editores.

Healey, P. (2004). The treatment of space and place in the new strategic spatial planning in Europe. In Steuerung und Planung im Wandel (pp. 297-329). VS Verlag für Sozialwissenschaften. DOI: 10.1007/978-3-322-80583-6_17

Incra (2018). Instituto Nacional de Colonização e Reforma Agrária. Reforma Agrária. http://www.incra.gov.br/reforma_agraria.

Incra (2017). Instituto Nacional de Colonização e Reforma Agrária. Assentamentos. http://www.incra.gov.br/assentamento.

Incra (2017). Instituto Nacional de Colonização e Reforma Agrária. Criação e Modalidades de Assentamentos. http://www.incra.gov.br/assentamentosmodalidades.

Ipam, Instituto de Pesquisa Ambiental da Amazônia (2016). Desmatamento nos Assentamentos da Amazônia: histórico, tendências e oportunidades, IPAM, Brasília, DF. https://ipam.org.br/bibliotecas/desmatamento-nos-assentamentos-da-amazonia-historico-tendencias-e-oportunidades/

Kaiser, E. J., Godschalk, D. R., \& Chapin, F. S. (1995). Urban land use planning (Vol. 4). Urbana: University of Illinois press.

Knieling, J., \& Othengrafen, F. (2009). Spatial planning and culture. Symbiosis for a better understanding of cultural differences in planning systems, Traditions and practices. Planning Cultures in Europe: Decoding Cultural Phenomena in Urban and Regional Planning, xxi-xxxv. Ashgate Publishing, Ltd.

Leal, A. L. (2016). A (s) resistência (s) ao grande projeto na Amazônia. Revista de Políticas Públicas, 85-103. ttp://dx.doi.org/10.18764/2178-2865.v20nEp85104

Lelis, M. G. A reserva extrativista Cazumbá-Iracema e a governança dos recursos comuns: sobrevivência de todos e patrimônio de uns? (2016). Tese (Doutorado em Extensão Rural). Minas Gerais: Universidade Federal de Viçosa.

Le Tourneau, F. M., \& BurszTyn, M. (2010). Assentamentos rurais na Amazônia: contradições entre a política agrária e a política ambiental. Ambiente \& Sociedade, 13, 111-130. DOI: 10.1590/S1414-753X2010000100008.

Metzger, J. P. (2001). Effects of deforestation pattern and private nature reserves on the forest conservation in settlement areas of the Brazilian Amazon. Biota neotropica, 1, 1-14. https://doi.org/10.1590/S1676-06032001000100003

Mma (2018). Ministério do Meio Ambiente. Unidades de Conservação: O que são. https://www.mma.gov.br/areas-protegidas/unidades-de-conservacao/oque-sao.html. 
Research, Society and Development, v. 10, n. 12, e318101220545, 2021 (CC BY 4.0) | ISSN 2525-3409 | DOI: http://dx.doi.org/10.33448/rsd-v10i12.20545

Mma (2018). Ministério do Meio Ambiente. Unidades de Conservação: Categorias. https://www.mma.gov.br/areas-protegidas/unidades-deconservacao/categorias.html

Moura, R. A. (2016). Novas, perspectivas para o desenvolvimento rural: uma análise normativa, conceitual e prática dos montes vicinais em mão comum galegos e das Unidades de conservação brasileiras. Tese (Doutorado em Extensão Rural). Minas Gerais: Universidade Federal de Viçosa.

Moraes, A. C. R (2005). Ordenamento Territorial: uma conceituação para o planejamento estratégico. In: Para pensar uma política nacional de ordenamento territorial. Anais da oficina sobre a Política Nacional de Ordenamento Territorial, Brasília, 13-14 de novembro de 2003. Brasília: MI, pp43-47.

Peres, R. B., \& de Almeida Chiquito, E. (2012). Ordenamento territorial, meio ambiente e desenvolvimento regional: novas questões, possíveis articulações. Revista Brasileira de Estudos Urbanos e Regionais, 14(2), 71-71. https://doi.org/10.22296/2317-1529.2012v14n2p71

Perroux, F. (1967). O desenvolvimento. In: DURAND, J. C. G. (Coord.). Sociologia do Desenvolvimento. Rio de Janeiro: Zahar Editores, pp17-25.

Quivy, R., \& Van Campenhoudt, L. (1998). Manual de investigação em ciências sociais. Rio de Janeiro: Gradiva.

Rabello, A. C. (2014). O golpe de Estado de 1964 e os impactos econômicos na Amazônia: continuidade e aprofundamento. História, memória e direitos humanos, 84 .

Raffestin, C. (1993). Por uma geografia do poder. São Paulo: Ática.

Rosário, R. R., Barbosa, M. T., da Silva Carneiro, F., \& Costa, M. D. S. S. (2021). Uso e ocupação do solo do município de novo progresso no Estado do ParáBrasil. Research, society and development, 10(1), e51210112060-e51210112060.

Rückert, A. A (2007). A Política Nacional de Ordenamento Territorial, Brasil. Uma política territorial contemporânea em construção. Scripta Nova. 245 (66). http://www.ub.edu/geocrit/sn/sn-24566.htm.

Salet, W., \& Faludi, A. (2000). Three approaches to strategic spatial planning. The revival of strategic spatial planning, $155,172$.

Santos, M. (1994). O retorno do território. Território: globalização e fragmentação, 4, 15-20.

Silva, A. F. C., Costa, M. D. S. S., Botelho, M. G. L., Furtado, L. G., de Almeida Batista, V., de Oliveira Carneiro, C. R., \& Morales, G. P. (2020). Impactos das alterações no uso e cobertura do solo no Município de Altamira, Pará. Research, Society and Development, 9(8), e303985488-e303985488.

Souza, M. J. L. D. (1995). O território: sobre espaço e poder, autonomia e desenvolvimento. Geografia: conceitos e temas. Rio de janeiro: Bertrand Brasil, 353, 77-116.

Souza, N. S. (2010). A Amazônia brasileira: processo de ocupação e a devastação da floresta. Boletim Científico ESMPU, Brasília, 32/33. http://boletimcientifico.escola.mpu.mp.br/boletins/boletim-cientifico-n.-32-33-janeiro-dezembro-2010/a-amazonia-brasileira-processo-de-ocupacao-e-adevastacao-da-floresta.

Steinhauer, C. (2011). International Knowledge Transfer: analysis of planning cultures. Reviewed Paᄀper. https://www.corp.at/archive/CORP2011_87.pdf. 